\title{
Crescimento Populacional, Evolução Econômica Recente e Capacidade de Polarização: um Estudo em Municípios de Minas Gerais
}

\section{Population Growth, Recent Economic Performance and Polarization: a Study at Municipal Level in the State of Minas Gerais}

\author{
Humberto Eduardo de Paula Martins ${ }^{1}$ \\ Luiz Bertolucci² \\ Polyana Lara de Oliveira ${ }^{3}$
}

\begin{abstract}
Resumo: O trabalho analisa o crescimento populacional, a evolução econômica recente, a especialização econômica e a capacidade de polarização em municípios selecionados de Minas Gerais. Primeiramente, buscam-se municípios que apresentaram crescimento populacional acima da taxa brasileira entre $1991 \mathrm{e}$ 2000 , e selecionam-se os mais relevantes em termos populacionais. Posteriormente, é analisada a evolução econômica recente dos municípios selecionados, observando a sua participação no emprego e no PIB nacionais. Por fim, são calculados o índice de terciarização e o quociente locacional. A análise dessas diversas variáveis, em conjunto, permite conhecer a realidade econômica dos municípios com significativo crescimento populacional e, assim, contribuir para o estudo das relações entre dinâmica populacional e evolução econômica.
\end{abstract}

Palavras-chave: Crescimento populacional. Polarização econômica. Minas Gerais.

Abstract: The study analyses populational growth, economic evolution, economic specialization and polarization capacity in selected municipal unities in Minas Gerais. Firstly, municipal unities that showed population growth between 1991 and 2000 higher than Brasilian average, and have significative population are selected for study. Then, economic evolution is analysed, based on jobs and PIB. At last, some indices are examined focusing on polarization capacity and

1 Professor do Instituto de Economia e do Programa de Pós-Graduação em Economia da Universidade Federal de Uberlândia (UFU).E-mail: hmartins@ufu.br

2 Economista do CEPES-IE/UFU, Mestre e Doutorando em Demografia pelo Centro de Desenvolvimento e Planejamento Regional da Universidade Federal de Minas Gerais (CEDEPLAR/ UFMG). Bolsista CNPq. E-mail: bertolucci@cedeplar.ufmg.br

3 Graduada em Ciências Econômicas pela Universidade Federal de Uberlândia e ex-Bolsista de Iniciação Científica PIBIC/CNPq. E-mail: polyecon@yahoo.com.br 
economic specialization. The analysis of these variables shows economic reality of municipal units with significative populational growth and then helps to studying of relations between populational dynamics and economic evolution.

Keywords: Populational growth. Economic polarization. Minas Gerais.

JEL Classification: R23; R11.

\section{Introdução}

As relações entre crescimento populacional e atividade econômica ocupam lugar de destaque nas pesquisas realizadas no Brasil. Mais recentemente, pesquisadores vêm procurando identificar as áreas de influência migratória com as áreas de influência dos pólos econômicos.

O presente trabalho procura contribuir com essa discussão, realizando uma investigação acerca do crescimento populacional e da evolução econômica recente de municípios selecionados em Minas Gerais, analisando a capacidade de polarização e a especialização econômica desses municípios. Mais especificamente, procura-se analisar e caracterizar essas dimensões econômicas de municípios de Minas Gerais que têm apresentado significativas taxas de crescimento populacional.

Além desta introdução, o trabalho é composto de outras quatro seções. Na segunda são apresentados, no contexto da literatura recente, o objetivo e a metodologia desenvolvida para esta pesquisa. Na terceira seção, faz-se uma caracterização demográfica dos municípios selecionados, destacando o crescimento populacional no período 1991-2000. A quarta seção analisa a evolução econômica recente desses municípios, com base na participação no total do emprego e do PIB nacionais. A quinta seção examina, por meio do índice de terciarização, a capacidade de polarização dos municípios selecionados, bem como a sua especialização setorial, utilizando o cálculo do quociente locacional. Ao final busca-se sintetizar e analisar conjuntamente os resultados, estabelecendo quadro comparativo dos municípios selecionados, considerando sua classificação em relação aos diversos indicadores analisados.

\section{2 Áreas de Atração Populacional e Polarização Econômica em Minas Gerais: Considerações Metodológicas}

No período recente, tem-se alterado significativamente o padrão histórico dos movimentos migratórios em Minas Gerais. Carvalho et al. (1998) assinalam que, a partir da década de 1970, Minas Gerais começou a mudar a sua característica de ser um Estado com forte predominância 
de emigração para outras regiões do Brasil. Com o declínio da emigração e o aumento da imigração, Minas Gerais tem demonstrado maior capacidade de retenção de sua população.

O Censo de 1991 mostrou que a imigração cresceu 30,6\% na década de 80 em Minas Gerais, chegando a 812.356 pessoas no decênio 1981-1991. As regiões que mais receberam população de outros Estados foram "justamente as que mais se expandiram economicamente: a Região Metropolitana de Belo Horizonte (23,5\%), Sul/Sudoeste de Minas $(18,9 \%)$ e Triângulo Mineiro/Alto Paranaíba (18,0\%)" (CARVALHO et al., 1998, p. 406).

Nesse quadro, vários trabalhos dedicaram-se a analisar as áreas de atração populacional em Minas Gerais. Dois trabalhos destacam-se como tentativas de analisar a atração populacional em pólos econômicos: Matos (1998) e Garcia et al. (2004).

Matos (1998) analisou a atração populacional de doze localidades definidas como pólos regionais pela Fundação João Pinheiro, conforme sua regionalização de 1985 (Uberlândia, Juiz de Fora, Montes Claros, Governador Valadares, Uberaba, Pouso Alegre/Itajubá, Divinópolis, Poços de Caldas, Teófilo Otoni, Varginha e Barbacena), além de Belo Horizonte e sua região metropolitana. Com base no Censo Demográfico de 1991, mostrou-se que, em geral, era importante a participação dos migrantes no período 1981-1991 na população total do ano de 1991 desses municípios: sempre superior a $10 \%$, chegando a $24,49 \%$, no caso de Uberlândia (MATOS, 1998, p. 716).

O autor chama a atenção para o fato de que esses percentuais adquirem maior expressão quando considerado o quadro de declínio da taxa de fecundidade que vem marcando o País desde fins dos anos 1960. Este declínio tem implicado numa redução do estoque de população jovem, justamente a faixa da população que, durante a década de 1970, esteve fortemente ligada ao número elevado de imigrantes.

Garcia et al. (2004) analisaram as áreas de influência migratória dos pólos econômicos nacionais em 1980, 1991 e 2000, considerando os movimentos populacionais ocorridos no quinquênio anterior a cada ano. Foram considerados pólos econômicos, "aquelas microrregiões que possuíam elevada concentração urbana e econômica, capazes de polarizar outras microrregiões", definidos em pesquisa anterior (LEMOS et al., 2000; LEMOS et al., 2003), em número de 84, sendo 11 macropólos e 73 mesopólos no Brasil. Em Minas Gerais, além de Belo Horizonte, situada entre os macropólos, cinco microrregiões estão posicionadas entre os "50 mesopólos mais dinâmicos em termos migratórios": Uberlândia, Juiz de Fora, Ipatinga, Governador Valadares e Montes Claros. Essas microrregiões apresentaram índices de migrantes por população total 
diferenciados, mas sempre com tendência decrescente na sequência dos três quinquênios: 1975-1980, 1986-1991 e 1995-2000.

O presente trabalho aborda as questões de crescimento populacional e polarização econômica em Minas Gerais com uma perspectiva diferente. Em vez de caracterizar a capacidade de atração populacional de municípios ou microrregiões considerados pólos econômicos, realiza-se o movimento inverso. Parte-se de municípios que demonstram indícios de atração populacional, para a análise de suas características econômicas, considerando seu potencial de polarização econômica.

A metodologia utilizada segue os seguintes passos:

I) Primeiramente, destacam-se os municípios que apresentaram crescimento populacional acima da taxa brasileira, e que, portanto, provavelmente, têm a migração como importante componente de seu crescimento populacional.

II) Em seguida, é analisada a evolução econômica recente desses municípios, observando a sua participação no emprego e no PIB nacionais. Nesse ponto, é analisada a correlação entre as participações dos municípios nos totais da população, do emprego e do PIB nacionais.

III) Posteriormente, são analisados o potencial de polarização, com base no cálculo do índice de terciarização para esses municípios, e a especialização econômica do município, utilizando o quociente locacional a partir de dados de emprego.

Para cada um desses indicadores ou índices, é estabelecida uma classificação, organizando os municípios em faixas, de acordo com os resultados obtidos.

IV) Elabora-se uma tabela-síntese que ordena os municípios de acordo com a taxa de variação da sua participação na população total do Brasil.

Assim, a proposta metodológica é baseada em índices simples e indicadores amplamente acessíveis, o que favorece sua utilização e difusão, de maneira que essa metodologia pode ser aplicada a outros conjuntos de municípios, referenciados em outras Unidades da Federação ou, ainda, em outras delimitações territoriais. Alguns desses procedimentos metodológicos são utilizados em Martins et al. (2007), trabalho que analisa comparativamente as tendências recentes de duas regiões de Minas Gerais (o Triângulo Mineiro e o Sul de Minas) com relação à migração e ao padrão de urbanização.

No presente trabalho, mais do que estabelecer relações quantitativas, buscam-se desenvolver caminhos para entender qualitativamente as relações entre os indicadores, estipulando parâmetros para classificação 
dos municípios em relação a sua evolução demográfica e econômica no período recente. Dessa maneira, a análise dessas variáveis, em conjunto, pretende contribuir para maior compreensão das relações entre crescimento populacional, evolução econômica, potencial de polarização e especialização econômica em nível municipal.

\section{Crescimento Populacional nos Municípios Selecionados}

Para a seleção dos municípios, são destacados aqueles cuja população cresceu a uma taxa superior à média nacional (1,64\% aa.), ou seja, os municípios mineiros que, provavelmente, apresentaram saldo migratório positivo durante o período 1991-2000. Neste primeiro corte foram selecionados 178 municípios. As taxas apresentadas por esses municípios são também superiores às taxas apresentadas por Minas Gerais ( $1,43 \%$ aa.) e pela capital, Belo Horizonte ( $1,16 \%$ aa.).

Visando focalizar os municípios mais relevantes em termos demográficos e econômicos, são selecionados os municípios que apresentavam 25 mil habitantes ou mais no ano 2000. A determinação deste nível de corte se deu de forma arbitrária, levando-se em consideração que os municípios pouco populosos possuem baixa capacidade de polarização. Assim, são selecionados 52 municípios, considerados relevantes em termos demográficos.

A população dos municípios selecionados varia entre 26 mil e 538 mil habitantes. Na Tabela 1 são apresentados os municípios, sua população em 1991 e 2000 e sua taxa média de crescimento da população, de acordo com a mesorregião em que se localizam.

A análise dos ritmos de crescimento dos municípios selecionados, definidos pelas taxas de crescimento populacional, mostra a existência de diversidade nesse conjunto de municípios. Alguns municípios chegaram a dobrar sua população ao longo da última década, constituindo-se, portanto, em novos espaços de atração populacional. Outros, inclusive alguns com expressivo contingente populacional, no entanto, cresceram em ritmo bem menos acelerado. 
Tabela 1 - Municípios Selecionados, População Total e Taxa Média de Crescimento da População (1991-2000)

\begin{tabular}{|c|c|c|c|c|}
\hline Mesorregião (Código) & Municípios & $\begin{array}{l}\text { População } \\
1991\end{array}$ & $\begin{array}{l}\text { População } \\
2000\end{array}$ & $\begin{array}{c}\text { Taxa de } \\
\text { Crescimento } \\
\text { Anual (\%) }\end{array}$ \\
\hline $\begin{array}{l}\text { Noroeste de Minas (1) } \\
\text { Norte de Minas (2) }\end{array}$ & $\begin{array}{c}\text { Paracatu } \\
\text { Jaíba* } \\
\text { Montes Claros } \\
\text { Janaúba } \\
\text { Taiobeiras }\end{array}$ & $\begin{array}{c}62.774 \\
17.889 \\
250.062 \\
50.229 \\
23.267\end{array}$ & $\begin{array}{c}75.216 \\
27.287 \\
306.947 \\
61.651 \\
27.347\end{array}$ & $\begin{array}{l}2,05 \\
4,85 \\
2,33 \\
2,32 \\
1,83\end{array}$ \\
\hline Jequitinhonha (3) & Capelinha & 25.561 & 31.231 & 2,27 \\
\hline $\begin{array}{l}\text { Triângulo Mineiro/ } \\
\text { Alto Paranaíba (5) }\end{array}$ & $\begin{array}{c}\text { São Gotardo } \\
\text { Uberlândia } \\
\text { Monte Carmelo } \\
\text { Uberaba } \\
\text { Patrocínio } \\
\text { Patos de Minas } \\
\text { Iturama }\end{array}$ & $\begin{array}{c}19.697 \\
367.061 \\
34.705 \\
207.345 \\
60.753 \\
102.946 \\
24.703 \\
\end{array}$ & $\begin{array}{c}27.631 \\
501.214 \\
43.899 \\
252.051 \\
73.130 \\
123.881 \\
28.814 \\
\end{array}$ & $\begin{array}{l}3,87 \\
3,56 \\
2,67 \\
2,21 \\
2,10 \\
2,10 \\
1,74 \\
\end{array}$ \\
\hline Central Mineira (6) & $\begin{array}{c}\text { Pompéu } \\
\text { Lagoa da Prata }\end{array}$ & $\begin{array}{l}20.350 \\
30.816 \\
\end{array}$ & $\begin{array}{l}26.089 \\
38.758 \\
\end{array}$ & $\begin{array}{l}2,83 \\
2,60 \\
\end{array}$ \\
\hline $\begin{array}{c}\text { Metropolitana } \\
\text { de Belo Horizonte (7) }\end{array}$ & $\begin{array}{c}\text { Esmeraldas } \\
\text { Betim } \\
\text { Ribeirão das Neves } \\
\text { Ibirité } \\
\text { Vespasiano } \\
\text { Lagoa Santa } \\
\text { Brumadinho } \\
\text { Santa Luzia } \\
\text { Pedro Leopoldo } \\
\text { Sabará } \\
\text { Sete Lagoas } \\
\text { Matozinhos } \\
\text { Nova Lima } \\
\text { Mariana } \\
\text { Contagem } \\
\text { Pará de Minas } \\
\text { Itabirito } \\
\text { Congonhas }\end{array}$ & $\begin{array}{c}24.298 \\
170.934 \\
143.853 \\
78.150 \\
47.991 \\
26.191 \\
19.308 \\
137.825 \\
41.594 \\
89.740 \\
144.014 \\
23.606 \\
52.400 \\
38.180 \\
449.588 \\
61.193 \\
32.091 \\
35.364\end{array}$ & $\begin{array}{c}47.090 \\
306.675 \\
246.846 \\
133.044 \\
76.422 \\
37.872 \\
26.614 \\
184.903 \\
53.957 \\
115.352 \\
184.871 \\
30.164 \\
64.387 \\
46.710 \\
538.017 \\
73.007 \\
37.901 \\
41.256\end{array}$ & $\begin{array}{l}7,70 \\
6,77 \\
6,24 \\
6,15 \\
5,36 \\
4,22 \\
3,66 \\
3,35 \\
2,96 \\
2,86 \\
2,84 \\
2,79 \\
2,34 \\
2,29 \\
2,03 \\
2,00 \\
1,88 \\
1,74 \\
\end{array}$ \\
\hline Vale do Rio Doce (8) & $\begin{array}{l}\text { Timóteo } \\
\text { Ipatinga }\end{array}$ & $\begin{array}{c}58.298 \\
180.069\end{array}$ & $\begin{array}{c}71.478 \\
212.496\end{array}$ & $\begin{array}{l}2,31 \\
1,87\end{array}$ \\
\hline Oeste de Minas (9) & $\begin{array}{l}\text { Nova Serrana } \\
\text { Divinópolis } \\
\text { Arcos } \\
\text { Itaúna }\end{array}$ & $\begin{array}{c}17.913 \\
151.462 \\
27.418 \\
66.395\end{array}$ & $\begin{array}{c}37.447 \\
183.962 \\
32.687 \\
76.862\end{array}$ & $\begin{array}{l}8,62 \\
2,20 \\
1,99 \\
1,66\end{array}$ \\
\hline
\end{tabular}




\begin{tabular}{c|c|c|c|c}
\hline & Pouso Alegre & 81.836 & 106.776 & 3,03 \\
& Alfenas & 52.700 & 66.957 & 2,72 \\
& Varginha & 88.022 & 108.998 & 2,43 \\
Sul/Sudoeste & São Lourenço & 29.870 & 36.927 & 2,41 \\
de Minas (10) & Poços de Caldas & 110.123 & 135.627 & 2,36 \\
& São Sebastião & & & 1,96 \\
& do Paraíso & 49.053 & 58.335 & 1,95 \\
& Santa Rita do Sapucaí & 26.317 & 31.264 & 1,95 \\
& Guaxupé & 39.611 & 47.036 & 1,70 \\
\hline Campo das Vertentes (11) & Andradas & 28.377 & 32.968 & 2,02 \\
\hline \multirow{2}{*}{ Zona da Mata (12) } & Lavras & 65.893 & 78.772 & 2,80 \\
& Ubá & 66.511 & 85.065 & 2,58 \\
& Viçosa & 51.658 & & 1,91 \\
& Juiz de Fora & 385.996 & 456.796 & 2,91 \\
& Conjunto dos municípios & & & 1,43 \\
& selecionados & 4.492 .000 & 5.815 .541 & 1,62
\end{tabular}

* O município de Jaíba foi criado em 1991 a partir da unificação dos municípios de Monte Azul e Manga.

Fonte: IBGE, Censos Demográficos de 1991 e 2000.

Dentre os municípios selecionados, alguns que estavam entre os de maior população em 1991 apresentaram expressivas taxas de crescimento anual: Uberlândia (3,5\% aa.); Santa Luzia (3,3\% aa.); Sete Lagoas (2,8\% aa.); Montes Claros (2,3\% aa.); Uberaba (2,2\% aa.); Contagem (2,0\% aa.) e Juiz de Fora (1,9\% aa.). As taxas revelam maior crescimento da população nos municípios periféricos da Região Metropolitana de Belo Horizonte e em municípios polarizadores de outras regiões, como o Sul de Minas e o Triângulo Mineiro. Há ainda alguns municípios de menor contingente populacional que mostram altas taxas de crescimento, como Jaíba, no Norte de Minas, e Nova Serrana, no Oeste. Geograficamente os municípios selecionados estão distribuídos entre 11 das 12 mesorregiões definidas pelo IBGE, para o Estado de Minas Gerais, conforme pode ser observado na Tabela 1. Apenas a mesorregião do Vale do Mucuri (código 4) não contou com município selecionado para este estudo.

A Mesorregião Metropolitana de Belo Horizonte reúne dezoito dos municípios selecionados, inclusive a maior parte deles apresentando taxas de crescimento anual elevadas, acima do crescimento médio dos municípios selecionados, como: Esmeraldas; Betim; Ribeirão das Neves; Ibirité; Vespasiano; e Lagoa Santa. Também destaca-se a Mesorregião Sul e Sudoeste de Minas, que reúne nove municípios, que não estão 
entre aqueles que apresentaram maior taxa de crescimento do Estado, excetuando-se o município de Pouso Alegre que cresceu a 3,03\% ao ano, no período 1991-2000. A Mesorregião do Triângulo Mineiro e Alto Paranaíba (Mesorregião, com sete municípios selecionados, destaca-se pelas taxas de crescimento apresentadas pelos municípios de São Gotardo (3,87\% aa.) e Uberlândia (3,56\% aa.).

O Mapa 1 apresenta a distribuição espacial desses municípios no Estado de Minas Gerais, de acordo com a faixa das taxas de crescimento anual no período, e permite observar os limites das mesorregiões conforme apresentado na Tabela 1. Pode-se perceber, pelo mapa e pela tabela, que há uma concentração dos municípios na Região Metropolitana de Belo Horizonte (Mesorregião 7). Tal fato associado à constatação de que o município de Belo Horizonte aumentou sua população a uma taxa de 1,16\% aa., menor que a do Brasil no período, pode indicar uma tendência de periferização da população metropolitana, que reforça a participação dos municípios no entorno da capital do Estado.

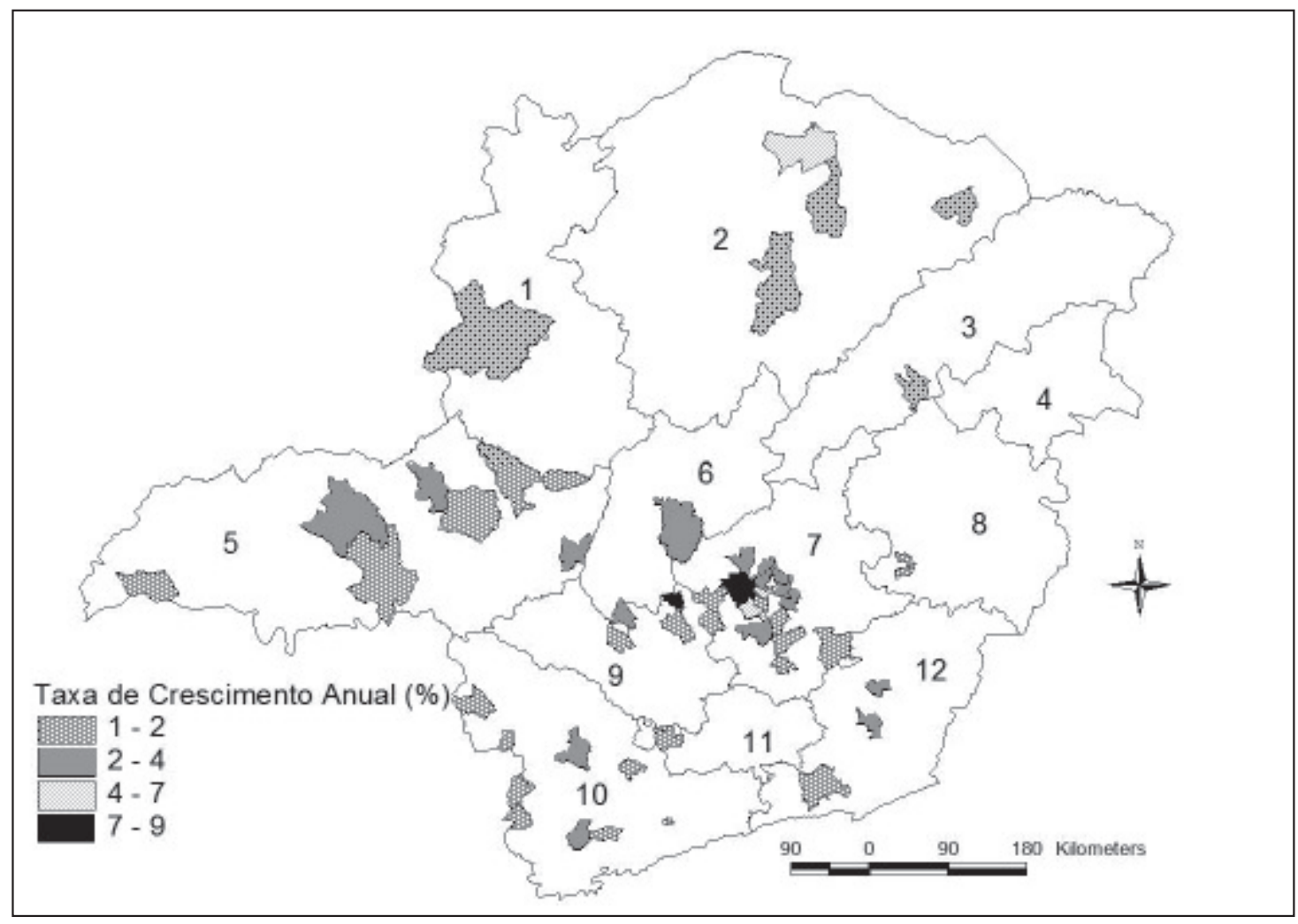

Mapa 1 - Taxas de crescimento anual da população residente nos municípios selecionados (\%)

Obs.: As mesorregiões estão numeradas de acordo com os códigos do IBGE. Fonte: Censos Demográficos de 1991 e 2000 - IBGE (elaboração própria). 


\section{Evolução Econômica Recente nos Municípios Selecionados: - Comportamento do Emprego e do PIB}

Nesta seção procura-se analisar a evolução econômica recente dos municípios analisados, com base em dados de emprego e PIB.

\subsection{Evolução do Emprego}

Em primeiro lugar, é analisada a evolução da participação desses municípios no total do Brasil, ao longo do período recente, como mostra a Tabela 2 .

A partir dos resultados encontrados, estabeleceu-se uma escala de classificação para os municípios selecionados. Dessa forma, dependendo da variação, em pontos percentuais, de sua participação no emprego total do Brasil, esses municípios podem ser classificados em quatro categorias:

I) Acentuado: municípios que tiveram acentuada elevação de sua participação (acima de 0,050);

II) Crescente: municípios que apresentam variação positiva relevante da participação no emprego (entre 0,050 e 0,010);

III) Estagnado: municípios que não apresentaram significativa alteração de sua participação (variação de 0,09 a 0,010);

IV) Decrescente: comporta os municípios que apresentaram acentuada redução da participação no emprego (redução maior que 0,010 pontos percentuais).

Tabela 2 - Participação dos Municípios Selecionados no Total do Emprego do Brasil, segundo classificação a partir da variação dessa participação - 1985-2000

\begin{tabular}{|c|c|c|c|c|c|c|}
\hline & \multicolumn{4}{|c|}{ Participação no Brasil (\%) } & \multirow[b]{2}{*}{$\begin{array}{c}\text { Variação da } \\
\text { participação } \\
\text { (em p.p.) } \\
1985-2000\end{array}$} & \multirow[b]{2}{*}{$\begin{array}{l}\text { Classificação } \\
\text { (em p.p.) }\end{array}$} \\
\hline Municípios & 1985 & 1990 & 1995 & 2000 & & \\
\hline $\begin{array}{l}\text { Uberlândia } \\
\text { Betim } \\
\text { Contagem }\end{array}$ & $\begin{array}{l}0,256 \\
0,127 \\
0,350\end{array}$ & $\begin{array}{l}0,294 \\
0,155 \\
0,375\end{array}$ & $\begin{array}{l}0,376 \\
0,226 \\
0,395\end{array}$ & $\begin{array}{l}0,387 \\
0,222 \\
0,412\end{array}$ & $\begin{array}{l}0,131 \\
0,095 \\
0,062\end{array}$ & $\begin{array}{c}\text { Acentuado } \\
\text { acima de } 0,050\end{array}$ \\
\hline
\end{tabular}




\begin{tabular}{|c|c|c|c|c|c|c|}
\hline & & & & & & \\
\hline Uberaba & 0,146 & 0,151 & 0,192 & 0,192 & 0,046 & \\
\hline Montes Claros & 0,117 & 0,133 & 0,149 & 0,160 & 0,043 & \\
\hline Patos de Minas & 0,045 & 0,050 & 0,065 & 0,080 & 0,035 & \\
\hline Divinópolis & 0,096 & 0,105 & 0,120 & 0,128 & 0,032 & \\
\hline Pouso Alegre & 0,053 & 0,069 & 0,068 & 0,084 & 0,031 & \\
\hline Ribeirão das Neves & 0,008 & 0,015 & 0,023 & 0,034 & 0,026 & \\
\hline Nova Serrana & 0,009 & 0,012 & 0,021 & 0,034 & 0,025 & \\
\hline Patrocínio & 0,023 & 0,027 & 0,036 & 0,046 & 0,023 & \\
\hline Poços de Caldas & 0,095 & 0,104 & 0,111 & 0,118 & 0,023 & \\
\hline Paracatu & 0,016 & 0,018 & 0,024 & 0,034 & 0,018 & Crescente \\
\hline Alfenas & 0,026 & 0,032 & 0,041 & 0,043 & 0,017 & de $0,050 \mathrm{a}$ \\
\hline Lavras & 0,034 & 0,043 & 0,048 & 0,050 & 0,016 & 0,010 \\
\hline São Sebastião do Paraíso & 0,022 & 0,029 & 0,032 & 0,038 & 0,016 & \\
\hline Ibirité & 0,010 & 0,015 & 0,021 & 0,025 & 0,015 & \\
\hline Monte Carmelo & 0,012 & 0,016 & 0,013 & 0,024 & 0,012 & \\
\hline Sabará & 0,019 & 0,024 & 0,028 & 0,031 & 0,012 & \\
\hline Ubá & 0,043 & 0,046 & 0,052 & 0,054 & 0,011 & \\
\hline Pará de Minas & 0,040 & 0,049 & 0,045 & 0,051 & 0,011 & \\
\hline Itabirito & 0,018 & 0,021 & 0,021 & 0,028 & 0,010 & \\
\hline Guaxupé & 0,026 & 0,030 & 0,033 & 0,036 & 0,010 & \\
\hline Varginha & 0,078 & 0,081 & 0,087 & 0,088 & 0,010 & \\
\hline Santa Rita do Sapucaí & 0,018 & 0,025 & 0,023 & 0,027 & 0,009 & \\
\hline Andradas & 0,013 & 0,017 & 0,019 & 0,021 & 0,008 & \\
\hline Janaúba & 0,011 & 0,010 & 0,012 & 0,019 & 0,008 & \\
\hline Esmeraldas & 0,004 & 0,008 & 0,014 & 0,012 & 0,008 & \\
\hline Sete Lagoas & 0,103 & 0,099 & 0,109 & 0,110 & 0,007 & \\
\hline Pedro Leopoldo & 0,030 & 0,034 & 0,035 & 0,035 & 0,005 & \\
\hline Taiobeiras & 0,002 & 0,008 & 0,004 & 0,007 & 0,005 & \\
\hline Jaíba* & - & 0,000 & 0,004 & 0,005 & 0,005 & \\
\hline Mariana & 0,014 & 0,017 & 0,018 & 0,019 & 0,005 & \\
\hline Capelinha & 0,004 & 0,006 & 0,006 & 0,009 & 0,005 & \\
\hline Pompéu & 0,006 & 0,005 & 0,008 & 0,011 & 0,005 & \\
\hline São Lourenço & 0,017 & 0,022 & 0,022 & 0,022 & 0,005 & \\
\hline Matozinhos & 0,015 & 0,018 & 0,016 & 0,019 & 0,004 & Estagnados \\
\hline São Gotardo & 0,007 & 0,007 & 0,006 & 0,010 & 0,003 & ( \\
\hline Arcos & 0,015 & 0,016 & 0,017 & 0,018 & 0,003 & \\
\hline Iturama & 0,013 & 0,010 & 0,015 & 0,015 & 0,002 & \\
\hline Santa Luzia & 0,047 & 0,051 & 0,052 & 0,048 & 0,001 & \\
\hline Ipatinga & 0,173 & 0,157 & 0,169 & 0,174 & 0,001 & \\
\hline Vespasiano & 0,029 & 0,030 & 0,032 & 0,028 & $-0,001$ & \\
\hline Congonhas & 0,022 & 0,025 & 0,025 & 0,020 & $-0,002$ & \\
\hline Brumadinho & 0,016 & 0,015 & 0,014 & 0,013 & $-0,003$ & \\
\hline Lagoa da Prata & 0,021 & 0,019 & 0,019 & 0,018 & $-0,003$ & \\
\hline Viçosa & 0,037 & 0,038 & 0,024 & 0,033 & $-0,004$ & \\
\hline Lagoa Santa & 0,023 & 0,022 & 0,028 & 0,019 & $-0,004$ & \\
\hline Nova Lima & 0,065 & 0,054 & 0,047 & 0,061 & $-0,004$ & \\
\hline Itaúna & 0,060 & 0,059 & 0,056 & 0,052 & $-0,008$ & \\
\hline
\end{tabular}




\begin{tabular}{c|c|c|c|c|c|c}
\hline Timóteo & 0,067 & 0,068 & 0,063 & 0,050 & $-0,017$ & Decrescente \\
Juiz de Fora & 0,390 & 0,389 & 0,381 & 0,364 & $-0,026$ & abaixo de $-0,010$ \\
\hline Municípios Selecionados & 2,894 & 3,124 & 3,464 & 3,638 & 0,744 & \\
Minas Gerais & 8,960 & 9,465 & 10,255 & 10,689 & 1,729 & \\
Brasil & 100,00 & 100,00 & 100,00 & 100,00 & - & \\
\hline
\end{tabular}

* O município de Jaíba foi criado em 1991 a partir da unificação dos municípios de Monte Azul e Manga.

Fonte: RAIS/MTE. Cálculos próprios.

Entre os anos de 1985 e 2000, os municípios selecionados apresentaram trajetórias diferenciadas em relação à sua participação no emprego total do Brasil. Entretanto, considerados em conjunto, os municípios selecionados apresentam, ao longo do período, significativa e crescente participação no total do emprego de Minas Gerais e do Brasil.

Os critérios para definição dos limites das categorias se baseiam na participação apresentada pelos municípios selecionados e na identificação de dinâmicas diferenciadas entre esses municípios. Pode-se perceber uma clara distinção entre os municípios de Uberlândia, Contagem, Betim, assim como de Timóteo e Juiz de Fora, em relação aos demais municípios: os três primeiros apresentaram significativa elevação de sua participação no total do emprego, e os dois últimos, significativa redução. Já na definição da distinção entre os municípios das categorias Crescente e Estagnado, trata-se de opção metodológica, cujos limites foram definidos de forma arbitrária.

Pode-se perceber que a maioria dos municípios selecionados se enquadra nos níveis de classificação de relativamente baixo crescimento da participação no total do emprego, classificados como crescentes e estagnados. Assim, embora esses municípios apresentem altas taxas de crescimento da população ao longo da década de 1990, nem todos tiveram um crescimento do emprego compatível com esse crescimento de população. É o caso, por exemplo, de Esmeraldas e Vespasiano que apresentaram algumas das maiores taxas de crescimento da população (acima de 5\% aa.), situando-se, no entanto, ambos os municípios no nível de classificação de crescimento do emprego Estagnado; chegando, inclusive, o segundo município a apresentar decréscimo, embora pouco significativo, de sua participação no emprego.

Dos quinze municípios com maiores taxas de crescimento da população (acima de 2,85\% aa.), nove apresentaram-se na categoria Estagnados quanto à variação do emprego. Dos restantes, dois apresentaram crescimento acentuado, e quatro tiveram algum crescimento, porém não acentuado.

Uberlândia destaca-se dentre os municípios selecionados por apresentar taxa de crescimento da população elevada (3,56\% a.a.) e variação 
significativa de sua participação no total do emprego do Brasil. Esse município apresenta também, conforme discutido em seção anterior, forte participação de migrantes no total de sua população. Contagem e Betim, na RMBH, também apresentam acentuado crescimento de sua participação no emprego, repetindo tendência demonstrada pela população e participação de migrantes. Por outro lado, os municípios de Timóteo e Juiz de Fora destacam-se pela acentuada redução da participação no emprego, embora tenham apresentado, como visto, significativo crescimento populacional.

\subsection{Evolução Recente do PIB}

A Tabela 3 apresenta dados referentes ao PIB dos municípios selecionados. Da mesma forma que ocorreu com relação aos dados de emprego, elabora-se uma escala de classificação para os municípios selecionados de acordo com a variação, em pontos percentuais, de sua participação no PIB total do Brasil:

I) Acentuado: municípios que tiveram acentuada elevação de sua participação (acima de 0,050 pontos percentuais);

II) Crescente: municípios que apresentam variação positiva relevante da participação no PIB do Brasil (entre 0,050 e 0,005);

III) Estagnado: municípios que não apresentaram significativa alteração de sua participação (variação de 0,004 a -0,010);

IV) Decrescente: comporta os municípios que apresentaram acentuada redução da participação no PIB (redução maior que 0,010 pontos percentuais).

Os critérios para definição dos limites das categorias se baseiam, assim como no caso do emprego, na identificação de dinâmicas diferentes entre os municípios analisados, e no caso das duas categorias intermediárias (Crescente e Estagnado), seu corte se deu de forma arbitrária.

Coerente com os resultados da população e do emprego, os municípios de Betim e Uberlândia tiveram o maior crescimento do PIB entre os anos de 1985-2000, apresentando-se também classificados na categoria acentuado de crescimento do PIB, assim como do emprego. O município de Contagem, no entanto, não manteve a mesma classificação do emprego (acentuado), pois apresentou pequena variação em pontos percentuais de sua participação no PIB do Brasil, sendo classificado na categoria estagnado. Outro município que se destaca é Juiz de Fora, que apresentou a maior redução da participação do emprego (categoria decrescente) e significativo aumento da participação no PIB (categoria crescente). Os demais municípios obtiveram resultados e classificação referentes ao PIB que são compatíveis com a classificação que tiveram em relação ao emprego. 
Tabela 3 - Participação dos Municípios Selecionados

no Total do Produto Interno Bruto (PIB) do Brasil

e Classificação segundo Variação dessa Participação (1985-2003)

\begin{tabular}{|c|c|c|c|c|c|}
\hline \multirow[b]{2}{*}{ Municípios } & \multicolumn{3}{|c|}{ Participação (\%) } & \multirow{2}{*}{$\begin{array}{c}\text { Variação } \\
\text { da participação } \\
\text { no PIB (em p.p.) } \\
\text { 1985-2000 }\end{array}$} & \multirow{2}{*}{$\begin{array}{l}\text { Classificação } \\
\text { (em p.p.) }\end{array}$} \\
\hline & 1985 & 1996 & 2000 & & \\
\hline $\begin{array}{c}\text { Betim } \\
\text { Uberlândia }\end{array}$ & $\begin{array}{l}0,523 \\
0,317\end{array}$ & $\begin{array}{l}0,339 \\
0,401\end{array}$ & $\begin{array}{l}0,872 \\
0,478\end{array}$ & $\begin{array}{l}0,349 \\
0,161\end{array}$ & $\begin{array}{c}\text { Acentuado } \\
\text { acima de } 0,050\end{array}$ \\
\hline $\begin{array}{c}\text { Ribeirão das Neves } \\
\text { Santa Luzia } \\
\text { Iturama } \\
\text { Montes Claros } \\
\text { Patos de Minas } \\
\text { Pouso Alegre } \\
\text { Juiz de Fora } \\
\text { Paracatu } \\
\text { Ibirité } \\
\text { Nova Serrana } \\
\text { Lavras } \\
\text { Sabará } \\
\text { Ubá } \\
\text { Jaíba* } \\
\text { Itabirito } \\
\text { Viçosa } \\
\text { Uberaba } \\
\text { Guaxupé } \\
\text { Matozinhos }\end{array}$ & $\begin{array}{r}0,019 \\
0,048 \\
0,024 \\
0,124 \\
0,046 \\
0,060 \\
0,273 \\
0,022 \\
0,021 \\
0,008 \\
0,029 \\
0,035 \\
0,026 \\
- \\
0,022 \\
0,012 \\
0,201 \\
0,028 \\
0,014\end{array}$ & $\begin{array}{l}0,029 \\
0,053 \\
0,013 \\
0,124 \\
0,055 \\
0,100 \\
0,320 \\
0,027 \\
0,018 \\
0,007 \\
0,039 \\
0,028 \\
0,031 \\
0,005 \\
0,039 \\
0,019 \\
0,171 \\
0,020 \\
0,013\end{array}$ & $\begin{array}{l}0,054 \\
0,070 \\
0,041 \\
0,140 \\
0,062 \\
0,072 \\
0,285 \\
0,033 \\
0,032 \\
0,018 \\
0,039 \\
0,045 \\
0,034 \\
0,008 \\
0,030 \\
0,019 \\
0,208 \\
0,034 \\
0,020\end{array}$ & $\begin{array}{l}0,035 \\
0,022 \\
0,017 \\
0,016 \\
0,016 \\
0,012 \\
0,012 \\
0,011 \\
0,011 \\
0,010 \\
0,010 \\
0,010 \\
0,008 \\
0,080 \\
0,008 \\
0,007 \\
0,007 \\
0,006 \\
0,006\end{array}$ & $\begin{array}{c}\text { Positivo } \\
\text { de } 0,050 \text { a } 0,005\end{array}$ \\
\hline $\begin{array}{l}\text { Pará de Minas } \\
\text { Esmeraldas } \\
\text { Taiobeiras } \\
\text { Lagoa da Prata } \\
\text { Sete Lagoas } \\
\text { Pedro Leopoldo } \\
\text { Contagem } \\
\text { Congonhas } \\
\text { São Gotardo } \\
\text { Pompéu } \\
\text { Capelinha } \\
\text { São Lourenço } \\
\text { Janaúba } \\
\text { Vespasiano } \\
\text { Arcos } \\
\text { Poços de Caldas } \\
\text { Monte Carmelo } \\
\text { Divinópolis } \\
\text { Mariana } \\
\text { São Sebastião do Paraíso } \\
\text { Alfenas } \\
\text { Andradas }\end{array}$ & $\begin{array}{l}0,038 \\
0,008 \\
0,003 \\
0,016 \\
0,100 \\
0,041 \\
0,481 \\
0,017 \\
0,011 \\
0,010 \\
0,008 \\
0,013 \\
0,014 \\
0,062 \\
0,019 \\
0,147 \\
0,022 \\
0,095 \\
0,038 \\
0,032 \\
0,044 \\
0,023\end{array}$ & $\begin{array}{l}0,028 \\
0,010 \\
0,003 \\
0,010 \\
0,083 \\
0,034 \\
0,353 \\
0,018 \\
0,007 \\
0,008 \\
0,009 \\
0,012 \\
0,008 \\
0,046 \\
0,019 \\
0,112 \\
0,021 \\
0,094 \\
0,018 \\
0,023 \\
0,036 \\
0,014\end{array}$ & $\begin{array}{l}0,042 \\
0,012 \\
0,005 \\
0,018 \\
0,101 \\
0,042 \\
0,482 \\
0,018 \\
0,011 \\
0,010 \\
0,008 \\
0,013 \\
0,014 \\
0,062 \\
0,018 \\
0,146 \\
0,020 \\
0,092 \\
0,033 \\
0,027 \\
0,039 \\
0,016\end{array}$ & $\begin{array}{l}0,004 \\
0,004 \\
0,002 \\
0,002 \\
0,001 \\
0,001 \\
0,001 \\
0,001 \\
0,000 \\
0,000 \\
0,000 \\
0,000 \\
0,000 \\
0,000 \\
-0,001 \\
-0,001 \\
-0,002 \\
-0,003 \\
-0,005 \\
-0,005 \\
-0,005 \\
-0,007\end{array}$ & $\begin{array}{c}\text { Estagnados } \\
\text { de } 0,004 \text { a }-0,010\end{array}$ \\
\hline
\end{tabular}

MARTINS, H. E. P.; BERTOLUCCI, L.; OLIVEIRA, P. L. Crescimento populacional, evolução... 


\begin{tabular}{c|l|l|l|l|l}
\hline Santa Rita do Sapucaí & 0,028 & 0,021 & 0,021 & $-0,007$ & \\
Lagoa Santa & 0,028 & 0,028 & 0,020 & $-0,008$ & Estagnados \\
Brumadinho & 0,028 & 0,014 & 0,018 & $-0,010$ & de 0,004 a -0,010 \\
Varginha & 0,096 & 0,073 & 0,086 & $-0,010$ & \\
\hline Patrocínio & 0,047 & 0,044 & 0,035 & $-0,012$ & \\
Itaúna & 0,060 & 0,038 & 0,042 & $-0,018$ & Decrescente \\
Nova Lima & 0,081 & 0,047 & 0,059 & $-0,022$ & abaixo de -0,010 \\
Timóteo & 0,148 & 0,065 & 0,096 & $-0,052$ & \\
Ipatinga & 0,389 & 0,211 & 0,229 & $-0,160$ & \\
\hline
\end{tabular}

* O município de Jaíba foi criado em 1991 a partir da unificação dos municípios de Monte Azul e Manga.

Fonte: PIB dos Municípios IPEA (1985-1996) e IBGE (2000-2003). Cálculos próprios.

\subsection{Correlação entre as variáveis}

Seguindo ideia de Andrade e Serra (2000), examinou-se a correlação existente entre as participações dos municípios selecionados no total nacional no ano 2000, nas três variáveis analisadas: população, emprego e PIB. Assim, procedeu-se ao cálculo das correlações linear (utilizando o Coeficiente de Pearson) e de ordem (com base no Coeficiente de Correlação de Spearman).

O coeficiente de correlação de Pearson é definido como:

$$
\mathrm{r}=\frac{\sum_{i=1}^{n}\left(x_{i}-\bar{x}\right)\left(y_{i}-\bar{y}\right)}{\sqrt{\sum_{i=1}^{n}\left(x_{i}-\bar{x}\right)^{2}} \sqrt{\sum_{i=1}^{n}\left(y_{i}-\bar{y}\right)^{2}}}
$$

Onde:

$\mathrm{x}_{1}, \mathrm{x}_{2}, \ldots, \mathrm{x}_{\mathrm{n}}$ e $\mathrm{y}_{1}, \mathrm{y}_{2}, \ldots, \mathrm{y}_{\mathrm{n}}$ são os valores de ambas variáveis.

Para além disso:

$$
\bar{x}=\frac{1}{n} \times \sum_{i=1}^{n} x_{i} \text { e } \bar{y}=\frac{1}{n} \times \sum_{i=1}^{n} y_{i}
$$

Já o coeficiente de correlação de Spearman é definido como:

$$
\rho=1-\frac{6 \sum d_{i}^{2}}{n\left(n^{2}-1\right)}
$$




\section{Onde:}

$n$ é o número de pares (xi,yi)

$d_{i}=$ (posto de xi dentre os valores de $\mathrm{x}$ ) - (posto de yi nos valores de $\mathrm{y}$ )

Os resultados obtidos foram os seguintes:

Tabela 4 - Correlação entre as participações dos municípios selecionados no total nacional de população, emprego e PIB (ano 2000)

\begin{tabular}{c|c|c|c}
\hline Coeficiente & População e Emprego & População e PIB & Emprego e PIB \\
\hline Correlação Linear (Pearson) & 0,951502055 & 0,776205654 & 0,804082000 \\
Correlação de Ordem (Spearman) & 0,999980568 & 0,999975258 & 0,999997493 \\
\hline
\end{tabular}

Fonte: Cálculos dos autores a partir de dados obtidos no IBGE, RAIS/MTE e IPEA.

Considerando o Coeficiente de Correlação Linear de Pearson, a correlação entre as participações dos municípios selecionados na população e no emprego formal apresenta resultado próximo de 1 , indicando que existe relação positiva e consistente entre a participação e, portanto uma associação forte entre a participação no total de habitantes e a participação no total de empregos formais do País. O valor referente à correlação entre as participações dos municípios na população e no PIB é bem menor, ou seja, a associação entre a participação do município nessas duas variáveis é menor, embora possa ser considerada razoável. A associação entre as participações no emprego e no PIB é mais fraca que a primeira analisada, no entanto é significativa, sendo maior que a anterior, indicando significativa associação entre a participação do município no PIB nacional e sua participação no emprego.

Já os resultados referentes aos coeficientes de correlação de ordem apresentam valores muito próximos de 1, indicando fortíssima associação entre as posições dos municípios quando ordenados em um ranking dos municípios selecionados segundo suas participações nos totais nacionais nas três variáveis.

Verifica-se, portanto, que a participação do município na população está fortemente associada a sua participação no emprego formal do País e, em grau bem menor, à sua participação do PIB nacional, embora a correlação de ordem tenha revelado valores altos para ambas. Já a associação entre sua participação no emprego formal do País e PIB nacional pode ser considerada significativa, em um patamar intermediário. 


\section{Capacidade de Polarização, Especialização Econômica e Classificação dos Municípios}

\section{1 Índice de Terciarização}

Procurando identificar tendências recentes acerca da polarização econômica dos municípios selecionados, utiliza-se o Índice de Terciarização (IT), calculado a partir de indicadores de Produto Interno Bruto (PIB), obtidos no Instituto de Pesquisa Econômica e Aplicada (IPEA):

$$
\mathrm{IT}=\frac{\text { PIB Serviços }}{\text { PIB Agropecuária }+ \text { PIB Indústria }}
$$

Esse índice permite observar o potencial de polarização do município, pois identifica a importância relativa do setor terciário (serviços e comércio), nos quais há uma identificação territorial entre produção e consumo, diferentemente dos setores de produtos transportáveis. De modo geral, esse índice está relacionado à capacidade que um município tem de atrair e reter renda, de maneira que os municípios que apresentam os índices de maiores valores (em especial os acima ou igual à unidade) tendem a desempenhar uma função de polarização econômica de seu entorno. Esse índice é usado em estudos acerca da regionalização, como Guimarães e Faria (2006).

A Tabela 5 mostra os índices de terciarização dos municípios selecionados para os anos de 1985, 1996, 2000 e 2003, em ordem decrescente dos valores para 2003.

Pode-se perceber que a ordem de apresentação dos municípios se altera novamente. O município de São Lourenço detém o maior índice de terciarização dentre os municípios selecionados. No entanto, este valor não indica que São Lourenço seria o mais forte polarizador, devendo-se mais à fraca participação dos setores primário e secundário no município que ao desempenho excepcional do terciário, pois com uma população pouco expressiva (abaixo dos 50 mil habitantes) é improvável que esse município exerça o papel de polarizador da região.

Foi também estabelecida uma classificação dos municípios selecionados a partir deste índice. São chamados de Pólos os municípios que apresentaram, para o ano de 2003, IT acima ou igual à unidade, e Não Pólos aqueles com IT abaixo da unidade. Dentre os municípios selecionados, metade apresentou IT acima da unidade, ou seja, 26 municípios podem ser classificados como Pólos e 26 como Não Pólos. 
Tabela 5 - Índice de Terciarização dos Municípios Selecionados 1985, 1996, 2000 e 2003

\begin{tabular}{|c|c|c|c|c|}
\hline Municípios & 1985 & 1996 & 2000 & 2003 \\
\hline \multicolumn{5}{|c|}{ Pólos } \\
\hline São Lourenço & 2,396 & 6,281 & 2,585 & 4,717 \\
\hline Viçosa & 2,812 & 6,032 & 2,063 & 2,398 \\
\hline Janaúba & 0,888 & 1,978 & 1,827 & 2,353 \\
\hline Ribeirão das Neves & 1,024 & 5,223 & 1,852 & 2,322 \\
\hline São Gotardo & 1,683 & 1,654 & 2,000 & 2,289 \\
\hline Taiobeiras & 1,605 & 4,632 & 1,680 & 2,266 \\
\hline Capelinha & 0,301 & 0,479 & 1,044 & 2,145 \\
\hline São Sebastião do Paraíso & 0,847 & 1,822 & 1,714 & 1,878 \\
\hline Esmeraldas & 0,697 & 1,070 & 1,408 & 1,698 \\
\hline Varginha & 1,104 & 1,734 & 1,609 & 1,533 \\
\hline Andradas & 0,787 & 0,730 & 1,165 & 1,490 \\
\hline Juiz de Fora & 1,361 & 2,586 & 1,165 & 1,400 \\
\hline Monte Carmelo & 0,749 & 0,485 & 1,025 & 1,366 \\
\hline Lagoa Santa & 1,292 & 1,010 & 1,327 & 1,324 \\
\hline Ubá & 0,523 & 1,322 & 1,283 & 1,324 \\
\hline Patrocínio & 0,974 & 0,482 & 1,144 & 1,274 \\
\hline Patos de Minas & 1,568 & 1,651 & 1,073 & 1,256 \\
\hline Lavras & 1,597 & 1,939 & 1,103 & 1,176 \\
\hline Contagem & 0,629 & 1,204 & 0,899 & 1,158 \\
\hline Montes Claros & 1,107 & 1,777 & 1,008 & 1,156 \\
\hline Alfenas & 0,462 & 1,811 & 0,936 & 1,115 \\
\hline Ibirité & 0,515 & 3,764 & 1,495 & 1,107 \\
\hline Uberlândia & 2,196 & 1,014 & 1,177 & 1,101 \\
\hline Divinópolis & 1,384 & 1,322 & 1,299 & 1,095 \\
\hline Pouso Alegre & 0,731 & 0,883 & 0,960 & 1,044 \\
\hline Nova Serrana & 0,380 & 1,444 & 0,930 & 1,031 \\
\hline
\end{tabular}




\begin{tabular}{c|c|c|c|c}
\hline \multicolumn{5}{c}{ Não Pólos } \\
\hline Jaíba* & - & 0,516 & 0,740 & 0,993 \\
Guaxupé & 0,523 & 1,812 & 0,913 & 0,960 \\
Santa Luzia & 0,420 & 1,532 & 0,896 & 0,904 \\
Lagoa da Prata & 0,446 & 1,098 & 0,970 & 0,892 \\
Pompeu & 0,579 & 0,595 & 0,840 & 0,870 \\
Pará de Minas & 1,249 & 1,617 & 0,863 & 0,840 \\
Itaúna & 0,469 & 1,467 & 0,912 & 0,828 \\
Sabará & 0,805 & 2,626 & 0,762 & 0,804 \\
Congonhas & 0,753 & 0,962 & 1,135 & 0,769 \\
Poços de Caldas & 0,393 & 0,738 & 0,692 & 0,752 \\
Paracatu & 1,552 & 0,916 & 0,781 & 0,712 \\
Santa Rita do Sapucaí & 0,294 & 0,686 & 0,709 & 0,689 \\
Sete Lagoas & 0,790 & 1,484 & 0,823 & 0,663 \\
Arcos & 0,415 & 0,426 & 0,837 & 0,663 \\
Pedro Leopoldo & 0,364 & 0,591 & 0,541 & 0,640 \\
Uberaba & 0,758 & 1,107 & 0,773 & 0,619 \\
Matozinhos & 0,543 & 0,595 & 0,612 & 0,521 \\
Betim & 0,603 & 0,291 & 0,427 & 0,480 \\
Vespasiano & 0,204 & 0,381 & 0,429 & 0,478 \\
Mariana & 0,279 & 0,665 & 0,501 & 0,465 \\
Nova Lima & 0,325 & 0,950 & 0,491 & 0,442 \\
Itabirito & 0,554 & 0,332 & 0,527 & 0,432 \\
Brumadinho & 0,543 & 0,673 & 0,556 & 0,428 \\
Ipatinga & 0,266 & 0,447 & 0,479 & 0,418 \\
Timóteo & 0,225 & 0,468 & 0,375 & 0,358 \\
Iturama & 0,700 & 0,655 & 0,333 & 0,290 \\
\hline
\end{tabular}

* O município de Jaíba foi criado em 1991 a partir da unificação dos municípios de Monte Azul e Manga.

Fonte: PIB dos Municípios IPEA (1985-1996) e IBGE (2000-2003).

\subsection{Quociente Locacional}

Para caracterizar a especialização setorial de cada município, utilizou-se o Quociente Locacional, calculado com base nos dados de emprego formal obtidos no espaço virtual do Ministério do Trabalho / RAIS. Esse índice mede a especialização setorial do município, em comparação com a distribuição setorial do emprego em nível nacional (ver HADDAD, 1989).

O índice foi calculado para os setores Indústria, Serviços e Agropecuária focalizando os anos de 1985 e 2005 . Para classificar os municípios de acordo com sua especialização, foi considerado o maior valor do QL dentre os setores:

$$
\text { QL setor }=\frac{\text { Emprego setor município } / \text { emprego total (formal) município }}{\text { Emprego setor nacional } / \text { emprego total (formal) nacional }}
$$


Os resultados estão expostos no Tabela 6.

Tabela 6 - Quociente Locacional da Indústria, Serviços e Agropecuária nos Municípios Selecionados para os anos de 1985 e 2005 (com base em dados do emprego formal)

\begin{tabular}{|c|c|c|c|c|c|c|c|c|c|}
\hline \multirow[t]{2}{*}{ Municípios } & \multirow[t]{2}{*}{$\begin{array}{l}\text { Classificação/ } \\
\text { Especialização }\end{array}$} & \multicolumn{2}{|c|}{ Indústria } & \multicolumn{2}{|c|}{ Serviços } & \multicolumn{2}{|c|}{ Agropecuária } & \multicolumn{2}{|c|}{$\begin{array}{l}\text { Outros/ } \\
\text { Ignorado }\end{array}$} \\
\hline & & 1985 & 2005 & 1985 & 2005 & 1985 & 2005 & 1985 & 2005 \\
\hline Alfenas & Agropecuária & 0,68 & 0,74 & 0,96 & 0,96 & 10,04 & 3,26 & 0,27 & 0,00 \\
\hline Andradas & Agropecuária & 1,69 & 1,49 & 0,66 & 0,63 & 2,01 & 4,81 & 0,41 & 0,00 \\
\hline Arcos & Indústria & 1,96 & 1,57 & 0,58 & 0,83 & 0,36 & 0,80 & 0,15 & 0,00 \\
\hline Betim & Indústria & 2,23 & 2,00 & 0,45 & 0,72 & 0,36 & 0,10 & 0,03 & 0,00 \\
\hline Brumadinho & Agropecuária & 1,57 & 1,30 & 0,74 & 0,88 & 1,64 & 1,35 & 0,07 & 0,00 \\
\hline Capelinha & Agropecuária & 0,09 & 0,26 & 1,50 & 0,71 & 0,00 & 10,75 & 0,53 & 0,00 \\
\hline Congonhas & Indústria & 1,97 & 1,17 & 0,59 & 0,98 & 0,01 & 0,28 & 0,02 & 0,00 \\
\hline Contagem & Indústria & 1,73 & 1,40 & 0,70 & 0,92 & 0,03 & 0,13 & 0,01 & 0,00 \\
\hline Divinópolis & Indústria & 1,39 & 1,46 & 0,86 & 0,87 & 0,44 & 0,55 & 0,15 & 0,00 \\
\hline Esmeraldas & Agropecuária & 0,43 & 0,68 & 1,13 & 0,93 & 8,13 & 4,14 & 0,42 & 0,00 \\
\hline Guaxupé & Agropecuária & 0,42 & 1,03 & 0,75 & 0,67 & 13,64 & 6,94 & 6,07 & 0,00 \\
\hline Ibirité & Indústria & 1,16 & 1,38 & 0,97 & 0,93 & 0,85 & 0,11 & 0,00 & 0,00 \\
\hline Ipatinga & Indústria & 1,83 & 1,79 & 0,65 & 0,79 & 0,01 & 0,11 & 0,01 & 0,00 \\
\hline Itabirito & Indústria & 1,92 & 1,90 & 0,60 & 0,74 & 0,35 & 0,42 & 0,09 & 0,00 \\
\hline Itaúna & Indústria & 1,92 & 1,72 & 0,56 & 0,78 & 1,47 & 0,60 & 0,19 & 0,00 \\
\hline Iturama & Agropecuária & 0,18 & 1,53 & 0,68 & 0,67 & 30,93 & 3,94 & 0,29 & 0,00 \\
\hline Jaíba* & Agropecuária & 0,00 & 0,31 & 0,00 & 0,92 & 0,00 & 6,55 & 0,00 & 0,00 \\
\hline Janaúba & Agropecuária & 0,72 & 0,65 & 0,93 & 0,89 & 7,32 & 5,18 & 2,07 & 0,00 \\
\hline $\begin{array}{l}\text { Juiz de Fora } \\
\text { Lagoa }\end{array}$ & Serviços & 1,06 & 0,94 & 1,03 & 1,06 & 0,13 & 0,34 & 0,10 & 0,00 \\
\hline da Prata & Indústria & 0,91 & 2,14 & 1,06 & 0,64 & 1,55 & 0,75 & 0,25 & 0,00 \\
\hline Lagoa Santa & Indústria & 0,48 & 1,19 & 1,32 & 0,97 & 0,12 & 0,41 & 0,09 & 0,00 \\
\hline Lavras & Agropecuária & 0,66 & 1,01 & 1,17 & 0,97 & 1,81 & 1,39 & 0,55 & 0,00 \\
\hline Mariana & Serviços & 1,52 & 0,84 & 0,79 & 1,08 & 0,64 & 0,40 & 0,06 & 0,00 \\
\hline $\begin{array}{l}\text { Matozinhos } \\
\text { Monte }\end{array}$ & Indústria & 2,03 & 2,26 & 0,55 & 0,59 & 0,38 & 0,95 & 0,03 & 0,00 \\
\hline $\begin{array}{l}\text { Carmelo } \\
\text { Montes }\end{array}$ & Agropecuária & 1,08 & 1,28 & 0,97 & 0,73 & 1,55 & 4,37 & 0,40 & 0,00 \\
\hline Claros & Indústria & 0,86 & 1,03 & 1,04 & 0,99 & 3,19 & 0,92 & 0,44 & 0,00 \\
\hline $\begin{array}{l}\text { Nova Lima } \\
\text { Nova }\end{array}$ & Indústria & 2,46 & 1,36 & 0,34 & 0,93 & 0,02 & 0,13 & 0,05 & 0,00 \\
\hline $\begin{array}{l}\text { Serrana } \\
\text { Pará de }\end{array}$ & Indústria & 2,46 & 3,18 & 0,30 & 0,33 & 1,04 & 0,28 & 0,32 & 0,00 \\
\hline Minas & Indústria & 1,63 & 1,52 & 0,67 & 0,73 & 3,05 & 2,80 & 0,18 & 0,00 \\
\hline $\begin{array}{l}\text { Paracatu } \\
\text { Patos de }\end{array}$ & Agropecuária & 0,71 & 0,61 & 1,11 & 0,86 & 3,77 & 5,86 & 0,30 & 0,00 \\
\hline Minas & Agropecuária & 0,48 & 0,80 & 1,23 & 0,97 & 2,84 & 2,84 & 0,45 & 0,00 \\
\hline $\begin{array}{l}\text { Patrocínio } \\
\text { Pedro }\end{array}$ & Agropecuária & 0,86 & 0,75 & 0,96 & 0,82 & 5,72 & 5,74 & 0,82 & 0,00 \\
\hline $\begin{array}{l}\text { Leopoldo } \\
\text { Pocos de }\end{array}$ & Agropecuária & 1,81 & 1,26 & 0,64 & 0,91 & 0,62 & 1,17 & 0,15 & 0,00 \\
\hline Caldas & Indústria & 1,16 & 1,31 & 0,90 & 0,91 & 3,18 & 0,78 & 0,21 & 0,00 \\
\hline
\end{tabular}




\begin{tabular}{|c|c|c|c|c|c|c|c|c|c|}
\hline Pompéu & Agropecuária & 0,95 & 1,42 & 0,85 & 0,73 & 9,27 & 3,49 & 0,21 & 0,00 \\
\hline Pouso Alegre & Indústria & 1,44 & 1,41 & 0,83 & 0,89 & 0,13 & 0,64 & 0,34 & 0,00 \\
\hline $\begin{array}{l}\text { Ribeirão } \\
\text { das Neves }\end{array}$ & Indústria & 1.17 & 115 & 0.98 & 0.99 & 0.22 & 0,31 & 0.00 & 0.00 \\
\hline Sabará & Indústria & 1,21 & 1,48 & 0,96 & 0,89 & 0,12 & 0,12 & 0,01 & 0,00 \\
\hline Santa Luzia & Indústria & 2,26 & 1,55 & 0,43 & 0,86 & 0,01 & 0,20 & 0,11 & 0,00 \\
\hline $\begin{array}{l}\text { Santa Rita } \\
\text { do Sapucaí }\end{array}$ & & & & & & & & & \\
\hline $\begin{array}{l}\text { do Sapucaí } \\
\text { São Gotardo }\end{array}$ & $\begin{array}{l}\text { Agropecuária } \\
\text { Aorone }\end{array}$ & $\begin{array}{l}1,37 \\
0,23\end{array}$ & 2,21 & 0,68 & $\begin{array}{l}0,51 \\
081\end{array}$ & $\begin{array}{l}5,20 \\
074\end{array}$ & $\begin{array}{l}2, / 4 \\
7,14\end{array}$ & $\begin{array}{l}1,05 \\
101\end{array}$ & $\begin{array}{l}0,00 \\
0,00\end{array}$ \\
\hline $\begin{array}{c}\text { São Gotardo } \\
\text { São }\end{array}$ & Agropecuária & 0,33 & 0,42 & 1,11 & 0,84 & 9,74 & 7,44 & 1,04 & 0,00 \\
\hline $\begin{array}{l}\text { Lourenço } \\
\text { São }\end{array}$ & Serviços & 0,62 & 0,55 & 1,24 & 1,18 & 0,22 & 0,33 & 0,27 & 0,00 \\
\hline Sebastião do & & & & & & & & & \\
\hline Paraíso & Agropecuária & 0,62 & 1,58 & 0,95 & 0,68 & 9,53 & 3,36 & 1,52 & 0,00 \\
\hline Sete Lagoas & Indústria & 1,51 & 1,60 & 0,79 & 0,82 & 0,67 & 0,64 & 0,14 & 0,00 \\
\hline Taiobeiras & Agropecuária & 0,44 & 1,39 & 1,22 & 0,85 & 3,80 & 1,49 & 0,60 & 0,00 \\
\hline Timóteo & Indústria & 2,03 & 1,90 & 0,56 & 0,75 & 0,00 & 0,22 & 0,00 & 0,00 \\
\hline Ubá & Indústria & 1,50 & 2,06 & 0,80 & 0,69 & 0,29 & 0,43 & 0,21 & 0,00 \\
\hline Uberaba & Agropecuária & 1,03 & 0,99 & 0,99 & 0,96 & 1,88 & 1,79 & 0,24 & 0,00 \\
\hline Uberlândia & Agropecuária & 0,70 & 0,87 & 1,14 & 1,03 & 2,53 & 1,22 & 0,40 & 0,00 \\
\hline Varginha & Agropecuária & 0,88 & 1,14 & 1,03 & 0,93 & 2,17 & 1,47 & 0,95 & 0,00 \\
\hline Vespasiano & Agropecuária & 2,27 & 1,59 & 0,37 & 0,86 & 2,40 & 0,06 & 0,02 & 0,00 \\
\hline Viçosa & Serviços & 0,18 & 0,51 & 1,45 & 1,16 & 0,91 & 0,92 & 0,22 & 0,00 \\
\hline Minas Gerais & Agropecuária & 0,99 & 1,04 & 1,02 & 0,95 & 1,63 & 1,64 & 0,27 & 0,00 \\
\hline Brasil & & 1,00 & 1,00 & 1,00 & 1,00 & 1,00 & 1,00 & 1,00 & 0,00 \\
\hline
\end{tabular}

* O município de Jaíba foi criado em 1991 a partir da unificação dos municípios de Monte Azul e Manga.

Fonte: RAIS/MTE. Cálculos próprios.

Os municípios selecionados apresentaram especialização principalmente nos setores Agropecuária, com 24 municípios, e Indústria, também com 24 municípios. Apenas quatro municípios foram classificados como especializados em Serviços. Percebe-se que os municípios da Região Metropolitana de Belo Horizonte foram classificados, em sua maioria, como de especialização em Indústria. No Sul de Minas, parte em Indústria, parte em Agropecuária e no Triângulo Mineiro, a totalidade como Agropecuária.

\subsection{Classificação dos Municípios com Base nos Resultados Obtidos}

Seguindo a proposta deste estudo, nesta subseção procura-se organizar os resultados, de maneira a permitir a análise conjunta das variáveis demográficas e econômicas apresentadas anteriormente. A Tabela 7 apresenta os municípios selecionados em ordem decrescente da variação, em pontos percentuais, de sua participação na população total do Brasil no período 1991-2000. Mais do que a taxa de crescimento 
da população, essa variação permite captar aqueles montantes de crescimento populacional que são efetivamente relevantes. Na tabela, são apresentadas classificações dos municípios quanto à participação dos migrantes na população residente, à evolução econômica recente (emprego e PIB), à capacidade de polarização e à especialização econômica (Índice de Terciarização e Quociente Locacional).

Pode-se observar que, em geral, quanto maior o crescimento da participação na população nacional, há uma tendência de melhor classificação na evolução econômica recente, com maior frequência das categorias Crescente e Acentuado na evolução da participação no emprego e no PIB nacionais, bem como das categorias de Pólo e de especialização na Indústria, ainda que haja diversas exceções. Assim, um primeiro elemento que a análise do quadro sugere é que o crescimento da participação na população nacional está relacionado com evolução econômica positiva e maior capacidade de polarização e especialização na Indústria, ainda que o comportamento dos municípios seja heterogêneo. Essa heterogeneidade permite propor uma organização dos municípios em grupos distintos, visando identificar padrões comuns. Considerando o crescimento da participação na população nacional e a classificação dos municípios nas várias categorias, podem ser estabelecidos três grupos.

O primeiro grupo seria formado pelos onze municípios que apresentaram maior crescimento da participação na população brasileira. Em geral esses municípios são bem classificados quanto à evolução econômica, bem como predominam a categoria Pólo e Especialização Industrial. Desses, oito fazem parte da RMBH, sendo que a maioria apresenta e classificações quanto ao emprego e PIB, nas categorias Crescente e Estagnado, dividindose entre Pólos e Não Pólos de Especialização Industrial. Os outros três municípios desse grupo, Uberlândia, Montes Claros e Nova Serrana, localizados fora da RMBH, estão bem classificados quanto à evolução econômica (Acentuado ou Crescente), e são considerados Pólos, os dois primeiros com especialização Agropecuária e o último na Indústria. 
Tabela 7 - Classificação dos Municípios Selecionados pelas Variáveis relacionadas à Evolução Econômica Recente (Emprego e PIB), Capacidade de Polarização (Índice de Terciarização) e Especialização Econômica (Quociente Locacional)

\begin{tabular}{|c|c|c|c|c|c|}
\hline Municípios & $\begin{array}{c}\text { Variação da } \\
\text { participação } \\
\text { da população }\end{array}$ & $\begin{array}{c}\text { Classificação } \\
\text { Emprego }\end{array}$ & $\begin{array}{c}\text { Classificação } \\
\text { PIB }\end{array}$ & $\begin{array}{c}\text { Classificação } \\
\text { (Capacidade } \\
\text { de Polarização) }\end{array}$ & $\begin{array}{l}\text { Classificação } \\
\text { (Especialização } \\
\text { Econômica) }\end{array}$ \\
\hline $\begin{array}{l}\text { Betim } \\
\text { Ribeirão das }\end{array}$ & 0,064 & Acentuado & Acentuado & Não Pólo & Indústria \\
\hline Neves & 0,047 & Crescente & Crescente & Pólo & Indústria \\
\hline Uberlândia & 0,045 & Acentuado & Acentuado & Pólo & Agropecuária \\
\hline Ibirité & 0,025 & Crescente & Crescente & Pólo & Indústria \\
\hline Santa Luzia & 0,015 & Estagnado & Crescente & Não Pólo & Indústria \\
\hline Vespasiano & 0,012 & Estagnado & Estagnado & Não Pólo & Indústria \\
\hline Esmeraldas & 0,011 & Estagnado & Estagnado & Pólo & Agropecuária \\
\hline Sete Lagoas & 0,011 & Crescente & Estagnado & Não Pólo & Indústria \\
\hline $\begin{array}{l}\text { Contagem } \\
\text { Montes }\end{array}$ & 0,011 & Acentuado & Estagnado & Pólo & Indústria \\
\hline $\begin{array}{l}\text { Claros } \\
\text { Nova }\end{array}$ & 0,010 & Crescente & Crescente & Pólo & Agropecuária \\
\hline Serrana & 0,010 & Crescente & Crescente & Pólo & Indústria \\
\hline $\begin{array}{l}\text { Uberaba } \\
\text { Pouso }\end{array}$ & 0,007 & Crescente & Crescente & Não Pólo & Agropecuária \\
\hline Alegre & 0,007 & Crescente & Crescente & Pólo & Indústria \\
\hline Sabará & 0,007 & Estagnado & Crescente & Não Pólo & Indústria \\
\hline Juiz de Fora & 0,006 & Decrescente & Crescente & Pólo & Serviços \\
\hline $\begin{array}{l}\text { Divinópolis } \\
\text { Poços de }\end{array}$ & 0,005 & Crescente & Estagnado & Pólo & Indústria \\
\hline Caldas & 0,005 & Crescente & Estagnado & Não Pólo & Indústria \\
\hline Ubá & 0,005 & Crescente & Crescente & Pólo & Indústria \\
\hline Lagoa Santa & 0,004 & Estagnado & Estagnado & Pólo & Indústria \\
\hline Varginha & 0,004 & Estagnado & Estagnado & Pólo & Agropecuária \\
\hline Jaíba & 0,004 & Estagnado & Crescente & Não Pólo & Agropecuária \\
\hline $\begin{array}{l}\text { Alfenas } \\
\text { Pedro }\end{array}$ & 0,004 & Crescente & Estagnado & Pólo & Agropecuária \\
\hline Leopoldo & 0,003 & Estagnado & Estagnado & Não Pólo & Indústria \\
\hline $\begin{array}{c}\text { Viçosa } \\
\text { São }\end{array}$ & 0,003 & Estagnado & Crescente & Pólo & Serviços \\
\hline $\begin{array}{l}\text { Gotardo } \\
\text { Patos de }\end{array}$ & 0,003 & Estagnado & Estagnado & Pólo & Agropecuária \\
\hline Minas & 0,003 & Crescente & Crescente & Pólo & Agropecuária \\
\hline Brumadinho & 0,003 & Estagnado & Estagnado & Não Pólo & Agropecuária \\
\hline Ipatinga & 0,003 & Estagnado & Decrescente & Não Pólo & Indústria \\
\hline Timóteo & 0,002 & Decrescente & Decrescente & Não Pólo & Indústria \\
\hline $\begin{array}{l}\text { Nova Lima } \\
\text { Monte }\end{array}$ & 0,002 & Estagnado & Decrescente & Não Pólo & Indústria \\
\hline Carmelo & 0,002 & Estagnado & Estagnado & Pólo & Indústria \\
\hline $\begin{array}{l}\text { Janaúba } \\
\text { Lagoa da }\end{array}$ & 0,002 & Crescente & Estagnado & Pólo & Agropecuária \\
\hline Prata & 0,002 & Estagnado & Estagnado & Não Pólo & Indústria \\
\hline
\end{tabular}




\begin{tabular}{|c|c|c|c|c|c|}
\hline Patrocínio & 0,002 & Crescente & Decrescente & Pólo & Agropecuária \\
\hline Matozinhos & 0,002 & Estagnado & Crescente & Não Pólo & Indústria \\
\hline Paracatu & 0,002 & Crescente & Crescente & Não Pólo & Agropecuária \\
\hline Lavras & 0,002 & Crescente & Crescente & Pólo & Agropecuária \\
\hline Mariana & 0,002 & Estagnado & Estagnado & Não Pólo & Serviços \\
\hline $\begin{array}{l}\text { Pompéu } \\
\text { São }\end{array}$ & 0,002 & Estagnado & Estagnado & Não Pólo & Agropecuária \\
\hline $\begin{array}{c}\text { Lourenço } \\
\text { Pará de }\end{array}$ & 0,001 & Estagnado & Estagnado & Pólo & Serviços \\
\hline Minas & 0,001 & Crescente & Estagnado & Não Pólo & Indústria \\
\hline $\begin{array}{l}\text { Capelinha } \\
\text { São }\end{array}$ & 0,001 & Estagnado & Estagnado & Pólo & Agropecuária \\
\hline $\begin{array}{l}\text { Sebastião } \\
\text { do Paraíso }\end{array}$ & 0,001 & Crescente & Estagnado & Pólo & Agropecuária \\
\hline Guaxupé & 0,001 & Estagnado & Crescente & Não Pólo & Agropecuária \\
\hline Arcos & 0,001 & Estagnado & Estagnado & Não Pólo & Indústria \\
\hline Santa Rita & & & & & \\
\hline do Sapucaí & 0,000 & Crescente & Estagnado & Não Pólo & Agropecuária \\
\hline Itabirito & 0,000 & Crescente & Crescente & Não Pólo & Indústria \\
\hline Taiobeiras & 0,000 & Estagnado & Estagnado & Pólo & Agropecuária \\
\hline Congonhas & 0,000 & Estagnado & Estagnado & Não Pólo & Indústria \\
\hline Iturama & 0,000 & Estagnado & Crescente & Não Pólo & Agropecuária \\
\hline Andradas & 0,000 & Estagnado & Estagnado & Pólo & Agropecuária \\
\hline Itaúna & 0,000 & Estagnado & Decrescente & Não Pólo & Indústria \\
\hline
\end{tabular}

Fonte: Elaboração própria com base em dados do IBGE - Censos Demográficos de 1991 e 2000 para população e demais variáveis, MTE/RAIS (emprego) e IPEA (PIB).

Já dentre os 24 últimos municípios apresentados, ocorre a predominância de indicadores menos favoráveis: baixo crescimento da participação na população, assim como do emprego e do PIB; prevalência da classificação; e de Não Pólos no IT e de especialização Agropecuária. Assim, embora sua população tenha crescido ligeiramente acima da taxa nacional, esses municípios revelam realidades mais próximas da estagnação econômica, com baixa capacidade de polarização e com nível menor de industrialização. Esses municípios distribuem-se por várias mesorregiões do Estado.

Entre esses dois extremos, há um grupo de 17 municípios, que apresentam crescimento próximo da variação da população, mas grande heterogeneidade dos indicadores, assim como de suas classificações, sendo mais difícil extrair um padrão a partir dos dados apresentados. Predominam a classificação, Crescente e Estagnado na evolução econômica, e há um equilíbrio tanto entre Pólos e Não Pólos, quanto entre as categorias de especialização econômica. 


\section{Considerações Finais}

A análise dos indicadores revela que, entre os municípios selecionados, ocorreu significativa disparidade de resultados em relação ao crescimento da população residente, à evolução das participações do município nos totais nacionais do emprego e do PIB, ao índice de terciarização e à especialização setorial. Assim, fica caracterizado que, embora todos os municípios tenham apresentado crescimento populacional acima da taxa nacional durante o período 1991-2000 e, portanto, aumentado sua participação no total da população brasileira, nos demais indicadores o desempenho não foi homogêneo no período recente, ainda que os resultados analisados sugiram associação entre os comportamentos positivos.

Mesmo não sendo suficiente para análises de fluxos e obtenção de saldos ou diferenças migratórias, a taxa de crescimento populacional intercensitária bem acima da taxa nacional em alguns municípios sugeriu, e de certa forma confirmou, que o Estado de Minas Gerais conta com áreas municipais funcionando como pólos relevantes de atração populacional.

No que se refere à evolução da participação do emprego do município no total nacional, no período 1985-2000, 23 municípios apresentaram desempenho significativamente positivo, sendo que em três deles (Uberlândia, Contagem e Betim), esse aumento foi altamente expressivo. Quanto à evolução da participação do PIB do município no total nacional, a maioria dos municípios mostrou desempenho positivo. No tocante ao índice de terciarização, cerca de metade mostrou índice acima da unidade na maior parte dos anos em que ele foi calculado.

Pode-se observar que o crescimento da participação na população nacional está, em geral, relacionado com a evolução econômica recente favorável e com a capacidade de polarização e especialização industrial. A análise dos indicadores no período recente mostra que o desempenho econômico recente e a capacidade de polarização são bastante variados dentre os municípios que apresentaram crescimento populacional acima da taxa nacional. Mesmo assim, a variação da participação na população nacional é um indicador que permite ordenar esses municípios e associar padrões de evolução econômica.

Para tentar a identificação de padrões, este trabalho propôs várias classificações para os municípios, que, analisadas em conjunto, conforme a ordem de variação da participação na população total nacional, permitiram o estabelecimento de três grandes grupos de municípios. $\mathrm{O}$ primeiro é formado pelos onze municípios com maior crescimento da participação na população nacional, em que os indicadores, em geral, são favoráveis. O segundo, composto por dezessete municípios, reúne 
uma grande heterogeneidade de resultados e classificações, situando-se em uma posição intermediária. O terceiro é constituído por 24 municípios que apresentaram desempenho desfavorável na maior parte dos indicadores.

A identificação do potencial de polarização dos municípios pelo índice de terciarização revelou que aqueles caracterizados como Pólos distribuem-se pelos três grupos, com larga predominância no primeiro (a exceção fica por conta de alguns municípios que fazem parte da $\mathrm{RMBH}$ ), pouca predominância no segundo e minoria no terceiro grupo.

Assim, embora sejam necessárias maiores investigação e análise de outros indicadores, pode-se identificar uma associação entre o crescimento da participação na população nacional, a evolução econômica recente, o potencial de polarização e a especialização industrial dentre os municípios selecionados. Dessa maneira, como sugestões de desdobramento deste trabalho, e de futuras linhas de pesquisa, podem ser apontadas as análises quantitativas, que busquem mensurar e precisar essas relações, bem como estabelecer novas classificações e tipologias que contribuam para o entendimento das relações entre crescimento populacional e características econômicas em nível municipal.

\section{Referências}

ANDRADE, T.; SERRA, R. Distribuição Espacial da Indústria: Possibilidades Atuais para sua Investigação. Estudos Econômicos. São Paulo, v. 30, n. 2, p. 207-231, 2000.

BERTOLUCCI, L. As migrações na mesorregião do Triângulo Mineiro e Alto Paranaíba. Belo Horizonte: Cedeplar/UFMG. Dissertação de Mestrado, 2001.

CARVALHO, J. A.; BRITO, F.; RIBEIRO, J.; RIGOTTI, J. Minas Gerais, uma nova região de atração populacional. In: SEMINÁRIO SOBRE A ECONOMIA MINEIRA, 8, 1998, Diamantina. Anais..., Diamantina: CEDEPLAR/UFMG,1998. p. 397-420.

DINIZ, C. C. Desenvolvimento poligonal no Brasil: nem desconcentração, nem contínua polarização. In: Nova Economia. Belo Horizonte, v. 3, n. 1, p. 35-64, 1993.

. A Nova Configuração Urbano-Industrial no Brasil. ENCONTRO NACIONAL DE ECONOMIA, 27, Anais..., 1999. p. 1341-1363.

FERREIRA, M. Rede de Cidades em Minas Gerais a partir da Realocação da Indústria Paulista. Nova Economia. Belo Horizonte: Número especial, 1996. p. 9-69.

GARCIA, R.; LEMOS, M.; CARVALHO, J. A. As transformações das áreas de influência migratória dos pólos econômicos brasileiros nos períodos 1980-1991 e 1991-2000. Revista Brasileira de Estudos Populacionais, v. 21, n. 2, jul./dez. p. 259-281, 2004.

GUIMARÃES, E.; FARIA, G. Integração e Desenvolvimento Regional: Uma proposta de regionalização em Minas Gerais. In: SEMINÁRIO SOBRE A ECONOMIA MINEIRA, 12, Anais..., CD-ROM, 2006. Sem paginação.

HADDAD, P. Medidas de localização e de especialização. In: HADDAD, Paulo. Economia Regional: Teorias e Métodos de Análise. Fortaleza: BNB/ETENE, 1989. p. 67-206. 
IPEA/IBGE/UNICAMP. Caracterização e tendências da rede urbana do Brasil: estudos básicos para a caracterização da rede urbana. Brasília: IPEA, 2002.

LEMOS, M.; DINIZ, C. C.; GUERRA, L. P.; MORO, S.; DINIZ, B.; BOSCHI, R. A Nova Geografia Econômica do Brasil: uma proposta de regionalização com base nos pólos econômicos e sua áreas de influência. In: SEMINÁRIO SOBRE A ECONOMIA MINEIRA, 9, 2000, Diamantina. Anais..., Diamantina: CEDEPLAR/UFMG, 2000.

LEMOS, M.; DINIZ, C. C.; GUERRA, L.; MORO, S. A Nova Configuração Regional Brasileira e sua Geografia Econômica. In: Estudos Econômicos, v. 33, n. 4, out./dez. p. 665-700, 2003.

MATOS, R. Migração e desconcentração demográfica nas principais áreas de atração populacional de Minas Gerais. In: ENCONTRO NACIONAL DE ESTUDOS POPULACIONAIS, 11, 1998, Caxambu. Anais..., Caxambu: ABEP, 1998. p. 713-728.

MARTINS, H.; BERTOLUCCI, L.; OLIVEIRA, P. Urbanização, Migração e Emprego: Uma análise de Municípios no Triângulo Mineiro e Sul de Minas. Revista Pesquisa 8 Debate, v. 18, n. 2 (32), p. 283-305, 2007.

Recebido em: 26/06/2008.

Aceito em: 22/07/2008. 